\title{
Saccharomyces cerevisiae yeasts $\beta$-glucan influence on wheat dough rheological properties
}

\author{
Sofya Marukhnenko ${ }^{1}$, Anton Gerasimov ${ }^{1}$, Vera Ivanova ${ }^{1,}$,, Oksana Golovinskaia ${ }^{1}$, \\ Ekaterina Antontceva2, Olga Pokatova ${ }^{1}$, Artyom Morozov", and Mark Shamtsyan ${ }^{2}$. \\ ${ }^{1}$ Saint Petersburg National Research University of Information Technology, Mechanics and Optics \\ (ITMO University), 191002, Lomonosova str. 9, Saint Petersburg, Russia \\ ${ }^{2}$ Saint-Petersburg State Institute of Technology, 190013, Moskovsky pr., 26, Saint-Petersburg, \\ Russia
}

\begin{abstract}
Yeast $\beta$-glucan is a promising biologically active polysaccharide for developing mass consumption functional food. This research uses the method to obtain $\beta$-glucan-containing preparations from cell walls of the yeast Saccharomyces cerevisiae, and studies the effect of the resulting concentrate on the rheological properties of wheat flour dough and the quality of finished products. During the analysis, both traditional and modern methods were applied to determine the rheological indicators of the flour and dough quality. The introduction of a concentrate obtained from the residual brewer's yeast Saccharomyces cerevisiae into the dough causes no significant effects on the characteristics of both semi-finished products and finished products. This opens new prospects for using yeast $\beta$-glucans as a functional additive in the development of bakery products.
\end{abstract}

\section{Introduction}

Due to the trend towards a healthy lifestyle and proper nutrition, consumers are becoming more and more interested in products with functional properties positively affecting the human health. Wheat bread and bakery products are widely consumed, while premium wheat flour lacks fibers. Therefore, the enrichment of wheat bread with complex polysaccharides is an urgent task, the solution of which is likely to contribute to the overall health of consumers. Currently, $\beta$-glucan is a sufficiently studied polysaccharide, with its sources being in various cereals, bacteria, yeast, fungi and algae [1].

The physiological functions of $\beta$-glucan are determined by the structure of its molecule, in particular the type and configuration of bonds between sugar residues and the degree of branching of the molecules [2]. The most biologically active form is $\beta-1,3 / 1,6$-glucan $[3,4]$, which is found in the cell wall of fungi and yeast. In terms of its structure, yeast $\beta$ glucan molecules are branched non-starch polysaccharides, the monomers of which are $\beta$ -

*Corresponding author: vaivanova@itmo.ru 
D-glucose residues linked by glycosidic bonds at positions 1 and 3 with side branches at positions 1 and 6 [5]. Unlike glucans from cereals, fungi and algae, yeast $\beta$-glucan is water insoluble [6]

The polysaccharide has a prebiotic effect, as it does not undergo hydrolysis in the upper gastrointestinal tract and serves as a nutrient substrate for the probiotic intestinal microbiota [7].

$\beta$-glucan can be fermented by the intestinal microflora to form short-chain fatty acids, which reduce cholesterol synthesis in the liver [8]. $\beta$-glucan also helps to reduce the glycemic index of the product by inhibiting the absorption of glucose from the rest of the carbohydrate component of food [9], and has immunostimulating properties [10-12].

According to FDA, a prebiotic dosage of $\beta$-glucan is $3 \mathrm{~g}$ per day or 4 servings of $0.75 \mathrm{~g}$ of $\beta$-glucan per serving. Such dosages have an effect on blood cholesterol levels, lowering them, as well as reducing the risk of vascular disease. norms established by the Commission of the Eurasian Customs Union declare the maximum daily intake of $\beta$-glucan is $1 \mathrm{~g}$ per day.

Thus, the introduction of $\beta$-glucan into food products of mass consumption, such as bakery products, allows creating new functional food products to prevent a number of diseases in a wide range of consumers.

The effect of a mushroom extract containing $\beta$-glucans on the rheological characteristics of wheat dough was studied by M. Frioui et al. [13]. In the course of the study, it was found that mushroom extract is suitable as a functional component with insignificant changes of organoleptic properties. It does not impair the quality of finished products, neither seriously affects the rheology of the dough.

Our study aims to determine the influence of the introduced functional component on the quality characteristics of finished products and semi-finished products.

The use of residual brewer's yeast, which is a waste of brewing production, as a source of $\beta$-glucan, in wheat bread technology, can be considered as a promising resource-saving technology.

\section{Materials and methods}

\subsection{Method for obtaining $\beta$-glucan from yeast cell walls.}

The object of the study was the residual brewer's yeast Saccharomyces cerevisiae. The method for extracting $\beta$-glucan was selected based on the research by Varelas et al. [14]. A $15 \%$ yeast suspension was prepared in distilled water with the addition of $3 \%$ sodium chloride. Autolysis was conducted for 24 hours at a temperature of $55{ }^{\circ} \mathrm{C}$ with constant stirring $(120 \mathrm{rpm})$. Enzymes were inactivated by exposing of autolysate to $85^{\circ} \mathrm{C}$ for 15 minutes. After autolysis and inactivation of yeast's own enzymes, the cell wall suspension was centrifuged (4500 rpm, $15 \mathrm{~min}$, Rotanta 460, Hettich, Germany), the precipitate was washed three times with distilled water, followed by centrifugation and stored at $+4{ }^{\circ} \mathrm{C}$ overnight. Alkaline extraction was performed by exposing the cell walls to $1 \mathrm{M}$ sodium hydroxide solution at a temperature of $80 \pm 5{ }^{\circ} \mathrm{C}$ for 2 hours. Subsequent acid extraction was performed using $0.5 \mathrm{M}$ acetic acid solution at $75 \pm 5{ }^{\circ} \mathrm{C}$ for 1 hour. After each stage, the suspension was centrifuged and the precipitate was washed three times with distilled water.

The moisture content in the final concentrate was determined, the concentrate was stored at $+4{ }^{\circ} \mathrm{C}$ overnight. 


\subsection{Quantitative determination of $\beta$-glucans in the resulting concentrate}

The concentrate was analyzed for $\beta$-glucan content by the enzymatic method using the $\beta$ glucan Assay Kit (Yeast \& Mushroom) (Megazyme, Ireland).

\subsection{The effect of $\beta$-glucan on the rheological characteristics of wheat dough}

The dough was analyzed using rheological instruments: alveograph (Chopin), farinograph and amylograph (Brabender) according to standard techniques (ICC 115 /, ICC 126/1, ICC 121). Measured parameters: water absorption, degree of dough softening, amylolytic activity of flour, dough elasticity, dough extensibility.

The resulting concentrate was added to the dough during kneading together with water in accordance with the measurement procedure. The following dosages were used: $0.8 \%$; $1.0 \%$ and $1.2 \% \beta$-glucan by weight of flour. Wheat dough without concentrate was used as a control sample. The mass of the applied concentrate was calculated taking into account the content of $\beta$-glucan in it. The dosages were determined based on a study by Mohebbi et al. [15], which investigates the effect of oat $\beta$-glucan on the properties of wheat dough. Thereby, the minimum dosage corresponds to the norms of Russian legislation, the average and maximum dosages enable to assess the possibility of using a functional additive in the production of exported products.

\subsection{Bread making process}

To determine the effect of the extract introduction on the organoleptic characteristics of the finished bread, the dough was prepared without a sponge stage with a fermentation duration of 150 minutes, with two kneading after 60 and 120 minutes. The control recipe for $100 \%$ flour contained $1.5 \%$ salt and $2 \%$ compressed yeast, based on the weight of the flour. The hydration of the dough was $60 \%$. After fermentation, the dough was divided into dough pieces weighing $600 \mathrm{~g}$ for molds and $330 \mathrm{~g}$ for hearths. Proofing was performed at a temperature of $35^{\circ} \mathrm{C}$ and a relative air humidity of $80 \%$ for 60 minutes, and then the bread was baked at initial temperature $220{ }^{\circ} \mathrm{C}$, followed by a decrease to $210{ }^{\circ} \mathrm{C}$ for 35 minutes for the pan and 28 minutes for the hearth bread. The finished bread was cooled at ambient conditions for 3 hours for subsequent measurements.

During the dough preparation, the temperature, acidity and moisture content of the dough were recorded. In the finished product, the porosity, volume, acidity, and moisture content of the crumb were determined.

Results from at least 3 independent experiments were statistically processed by Excel 365. A p-value $<0.05$ was regarded as significant

\section{Results and discussion}

The content of $\beta-1,3 / 1,6$-glucan in the resulting concentrate was $45.7 \%$ of dry matter. The dry matter yield was $10,4 \%$ from dry yeasts biomass.

\subsection{Farinograph measurements}

Using a Farinograph (Brabender), the changes in water absorption, dough stability and dough formation time were investigated. The data are presented in Figure 1 and Table 1.

The test results show that the introduction of the concentrate increases the water absorption rate by $4 \%$, which can positively affect the technological characteristics in the 
production of products, in particular, the yield of finished products. Overall, $\beta$-glucan did not significantly affect the performance of the test sample compared to the control sample.

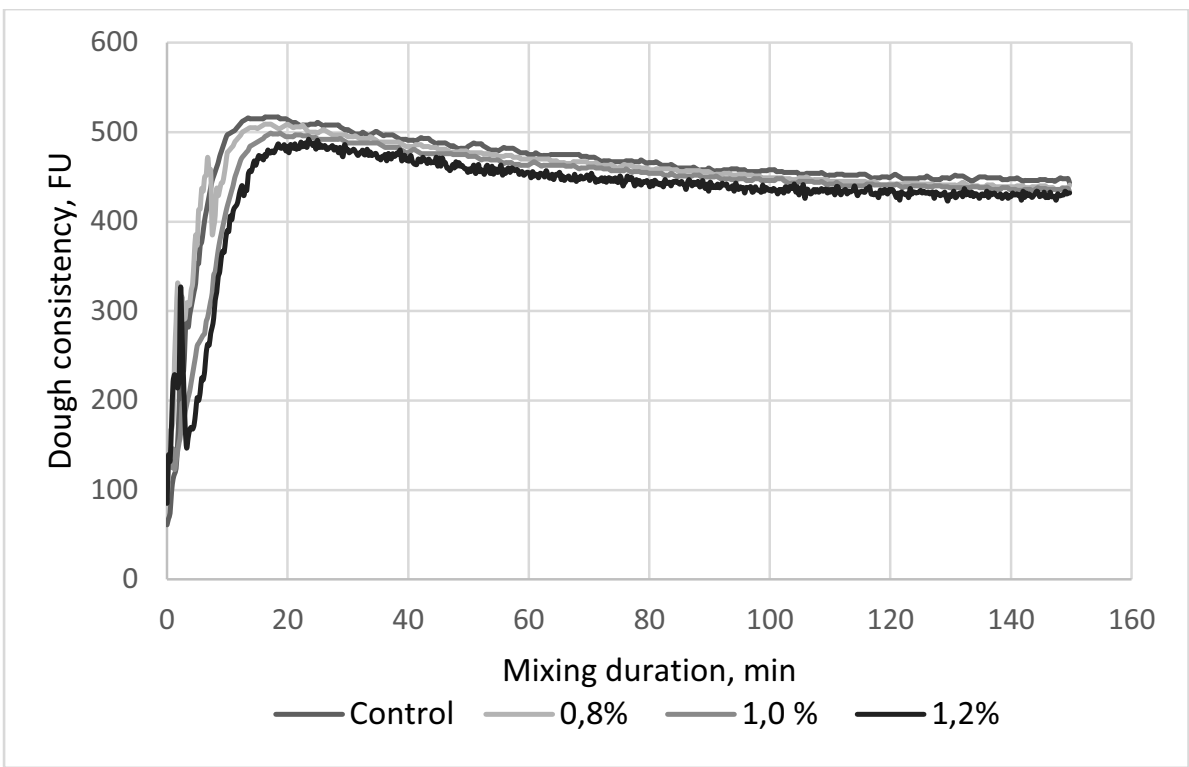

Fig.1. Farinograph curves.

Table 1. Farinograph characteristics of dough supplemented with $\beta$-glucan

\begin{tabular}{|c|c|c|c|c|}
\hline Sample & Control & $0.8 \%$ & $1.0 \%$ & $1.2 \%$ \\
\hline Flour moisture, \% & \multicolumn{4}{|c|}{11.4} \\
\hline Water absorption (ad.to 500 FU), \% & 63.4 & 67.2 & 67.7 & 68.0 \\
\hline Development time, min & 2.5 & 2.5 & 2.7 & 3.3 \\
\hline Stability, min & 7.6 & 6.6 & 6.6 & 6.2 \\
\hline $\begin{array}{c}\text { Degree of softening } \\
\text { (10 min after start), FU }\end{array}$ & 50 & 49 & 42 & 37 \\
\hline $\begin{array}{c}\text { Degree of softening } \\
\text { (ICC/ 12 min after max) FU }\end{array}$ & 62 & 64 & 55 & 50 \\
\hline $\begin{array}{c}\text { Farinograph quality number } \\
\text { (IC) }\end{array}$ & 62 & 62 & 73 & 83 \\
\hline
\end{tabular}

\subsection{Alveograph measurements}

Using an alveograph (Chopin), the elasticity and extensibility of the dough were determined. Instrument readings are presented in Table 2 and Figure 2

The results of the study on the alveograph show that as the dosage increases, the dough strengthens, which is indicated by the $\mathrm{P} / \mathrm{L}$ index characterizing the ratio of the elasticity of 
the dough to its extensibility. This effect can be useful in the production of baked goods with low moisture content, or products that require flour with short-growing gluten.

Table 2. Alveograph characteristics of dough supplemented with $\beta$-glucan

\begin{tabular}{|c|c|c|c|c|}
\hline Sample & Control & $0.8 \%$ & $1.0 \%$ & $1.2 \%$ \\
\hline Flour moisture, \% & \multicolumn{4}{|c|}{11.4} \\
\hline P (Elasticity), mm w.g. & 124 & 156 & 175 & 182 \\
\hline L (Extensibility), mm & 67 & 60 & 53 & 39 \\
\hline P/L & 1.9 & 2.6 & 3.3 & 4.7 \\
\hline G & 18.2 & 17.2 & 16.2 & 13.9 \\
\hline W, ${ }^{*} 10^{-4}$ & 306 & 353 & 364 & 295 \\
\hline
\end{tabular}

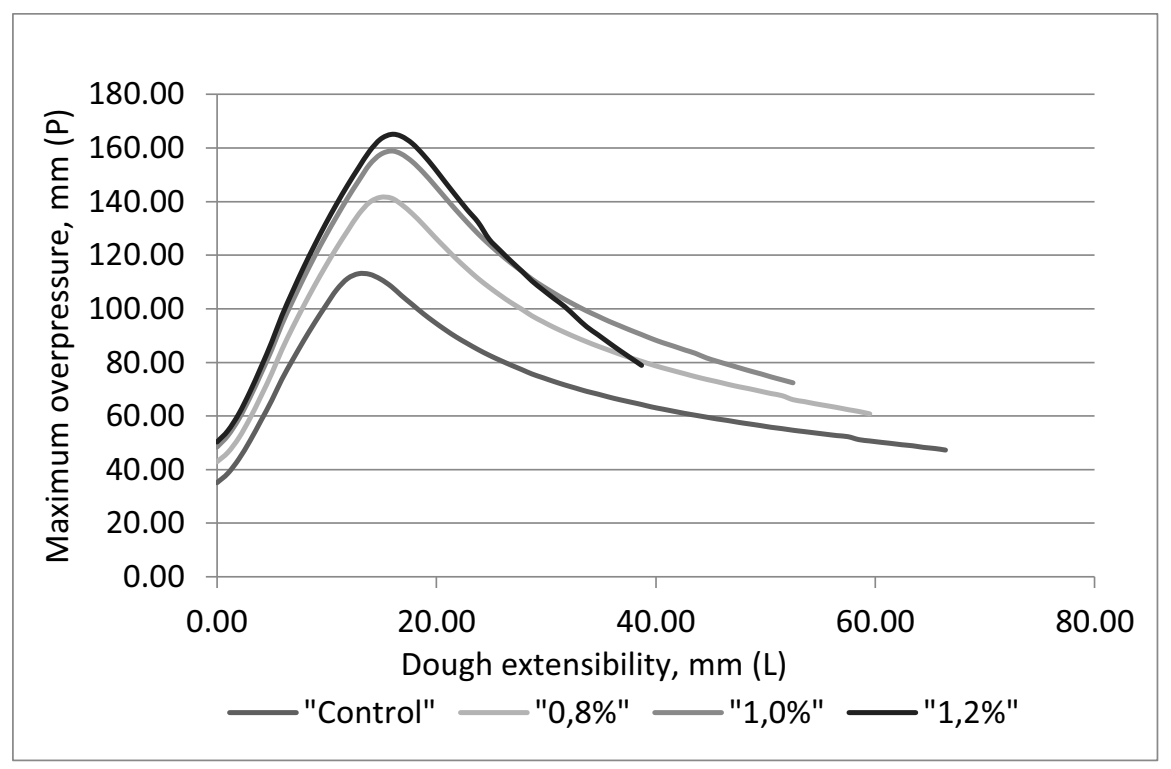

Fig.2. Alveograph curves.

\subsection{Amilograph measurements}

An amylograph (Brabender) was used to determine the effect of the extract introduction on the amylolytic activity of flour. Initial temperature was $30^{\circ} \mathrm{C}$, heating rate is 1.5 degrees per minute.

In the course of the research, an increase in the viscosity of the water-flour suspension was observed, which may be associated with the structure-forming properties of this polysaccharide. The addition of the concentrate did not significantly affect the temperatures of the onset and maximum of gelatinization. 
Table 3. Amilograph characteristics of dough supplemented with $\beta$-glucan

\begin{tabular}{|c|c|c|c|c|}
\hline Sample & Control & $0.8 \%$ & $1.0 \%$ & $1.2 \%$ \\
\hline Flour moisture, \% & \multicolumn{4}{|c|}{11.4} \\
\hline $\begin{array}{c}\text { Temperature of the } \\
\text { beginning of } \\
\text { gelatinization, }{ }^{\circ} \mathrm{C}\end{array}$ & 61.3 & 60.3 & 60.5 & 60.5 \\
\hline $\begin{array}{c}\text { Temperature of } \\
\text { gelatinization, }{ }^{\circ} \mathrm{C}\end{array}$ & 84.5 & 86.8 & 86.6 & 86.8 \\
\hline $\begin{array}{c}\text { Maximum gelatinization, } \\
\text { AU }\end{array}$ & 823 & 913 & 942 & 958 \\
\hline
\end{tabular}

\subsection{Laboratory baking results}

The dough was analyzed for moisture and acidity, the results are shown in Table 4.

Table 4. Physical and chemical indicators of the dough supplemented with $\beta$-glucan

\begin{tabular}{|c|c|c|c|c|}
\hline Sample & Control & $0.8 \%$ & $1.0 \%$ & $1.2 \%$ \\
\hline Dough moisture, \% & 42.8 & 42.7 & 42.5 & 42.3 \\
\hline Initial acidity, deg & 1.8 & 2.0 & 2.2 & 2.3 \\
\hline Final acidity, deg & 2.7 & 2.8 & 2.9 & 3.3 \\
\hline
\end{tabular}

There was a decrease in the moisture content of the dough by $0.5 \%$, as well as an increase in the initial acidity by 0.5 degrees.

In finished products, after 3 hours after baking, the acidity and moisture content of the crumb, porosity, dimensional stability, and volume were measured. The measurement results are presented in Table 5.

A decrease in the moisture content of the crumb by $1 \%$ and a decrease in porosity by $4 \%$ were noted, which is associated with the partial absorption of water by $\beta$-glucan molecules. The acidity of the crumb of the test samples did not differ from the control sample.

Organoleptic indicators were determined on a 5-point scale by a group of tasters, consisting of five people. Such indicators of the finished product as appearance, volume, color of bread crust, crumb color, crumb condition, taste, and smell were evaluated.

The results of the organoleptic evaluation revealed that the prototypes were not inferior in taste to the control bread. The most pronounced taste and smell had the product with the maximum dosage of $\beta$-glucan. The products did not have any foreign flavor and odors. 
Table 5. Physical and chemical indicators of the finished product

\begin{tabular}{|c|c|c|c|c|}
\hline Sample & Control & $0.8 \%$ & $1.0 \%$ & $1.2 \%$ \\
\hline Crumb acidity, deg & 1.6 & 1.6 & 1.6 & 1.6 \\
\hline Crumb moisture, \% & 42.3 & 42.0 & 41.4 & 40.3 \\
\hline Porosity, \% & 83.0 & 81.0 & 79.0 & 79.0 \\
\hline Form stability of hearth bread & 0.56 & 0.50 & 0.55 & 0.50 \\
\hline Specific volume $\mathrm{cm}^{3} / \mathrm{g}$ & 3.9 & 3.6 & 3.4 & 3.3 \\
\hline
\end{tabular}

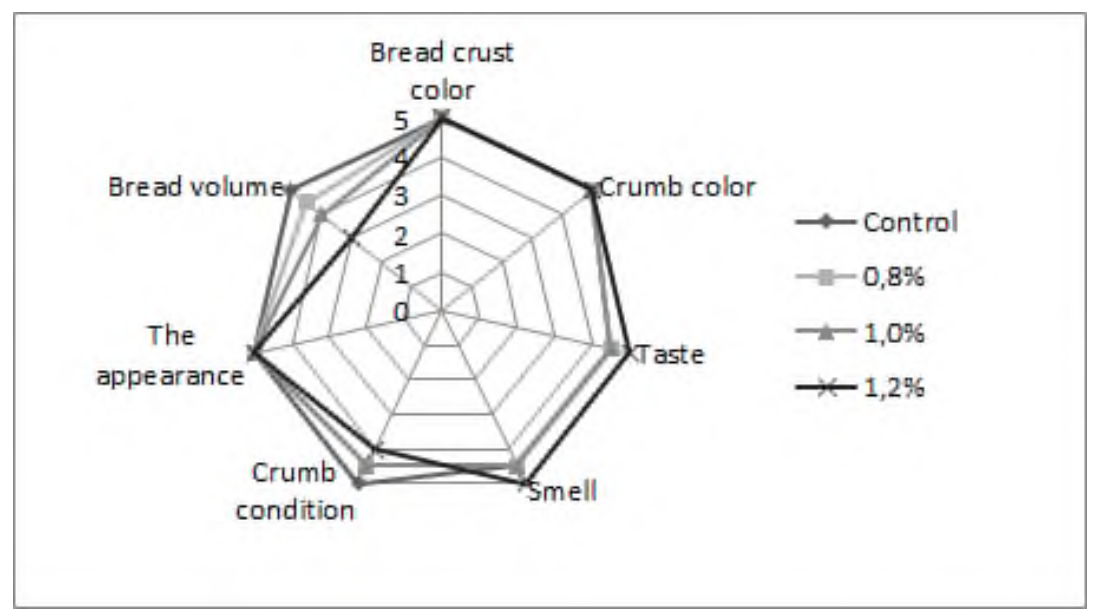

Fig.3. Organoleptic profile of finished products.

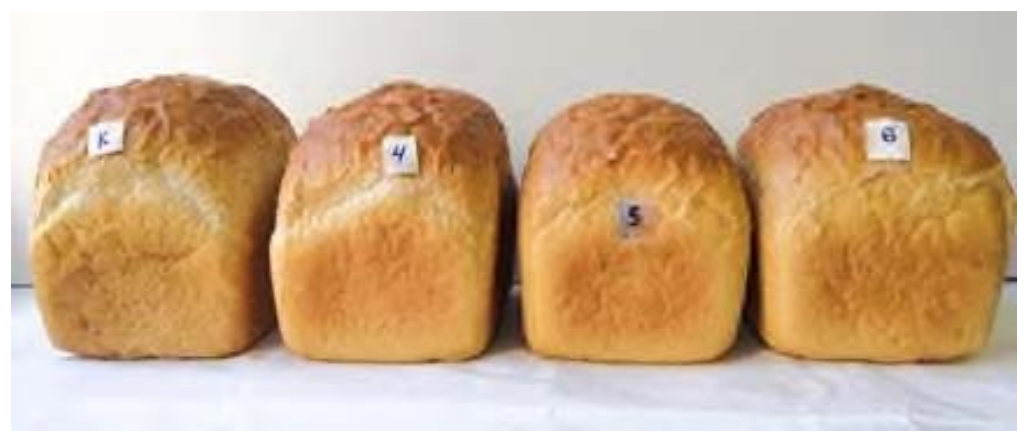

Fig.4. Appearance of finished bread. K-Control, 4- 0.8\%, 5- 1.0\%, 6-1.2\%. 


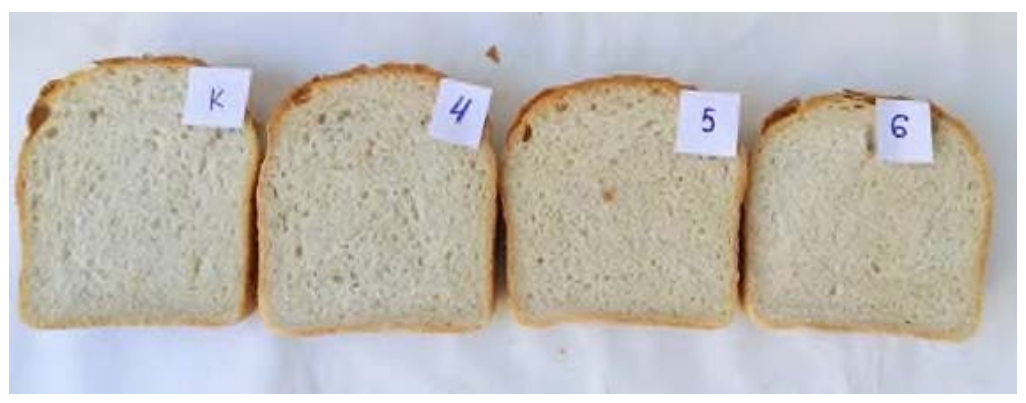

Fig.5. Sectional finished products. K- Control, 4- 0.8\%, 5- 1.0\%, 6-1.2\%.

The results of baking demonstrated that with an increase in the dosage of the applied concentrate, the moisture content of the bread crumb and the specific volume of the finished product decreased, which is a consequence of the partial absorption of water by $\beta$ glucan molecules.

\section{Conclusion}

The $\beta$-glucan concentrate, obtained from the yeast Saccharomyces cerevisiae, does not significantly affect the rheological characteristics of wheat dough, as well as the quality of finished products. This allows to use it as a functional additive for types of bakery products. The use of residual brewer's yeast as a source for the production of $\beta$-glucan concentrate opens an opportunity for a sustainable way to recycle brewing industry waste, as well as to develop new functional products.

\section{References}

1. F. Zhu, B. Du, Z. Bian, Xu B. Journal of Food Composition and Analysis, 41, pp. 165173 (2015). DOI: 10.1016/j.jfca.2015.01.019

2. B. Du, BJ. Xu, Bioactive Carbohydrates and Dietary Fibre, 3, pp. 11-16 (2014). DOI: $10.1016 /$ j.bcdf.2013.12.001

3. N. Dalonso, G. H. Goldman, R. M. M. Gern, Applied Microbiology and Biotechnology, 99 (19), pp.7893 -7906 (2015). DOI: 10.1007/s00253-015-6849-x

4. S. Rahar, G. Swami, N. Nagpal, M.A. Nagpal, G.S. Singh, Journal of Advanced Pharmaceutical Technology \& Research, 2, pp. 94-103 (2011). DOI: 10.41031/22314040.82953A.

5. B. K. McFarlin, K. C. Carpenter, T. Davidson, M. A. McFarlin, Journal of Dietary Supplements, 10(3), pp. 171-183 (2013). DOI: 10.3109/19390211.2013.820248

6. O. Rop, J. Mlcek, T. Jurikova, Nutrition Reviews, 67(11), pp. 624-631 (2009). DOI: 10.1111/j.1753-4887.2009.00230.x

7. B.R. Hamaker, Y.E. Tuncil, Journal of Molecular Biology, 426(23), pp. 3838-3850 (2014). DOI: 10.1016 / j.jmb.2014.07.028

8. S. A. Reis, L. L. Conceição, D. D. Rosa, N. P. Siqueira, M. C. G. Peluzio, Nutrition Research Reviews, 30, pp. 36-49 (2017). DOI: 10.1017/S0954422416000226

9. K.J. Shelat, F. Vilaplana, T.M. Nicholson, M.J. Gidley, R.G. Gilbert, Carbohydrate Polymers, 86 (4), pp. 1732- 1738 (2011). DOI: 10.1016/j.carbpol.2011.07.004 
10. V. Vetvicka, S. Petr, V. Luca, Therapeutic Foods. Handbook of Food Bioengineering, 8 (8), pp. 239-256 (2017). DOI: 10.1016/B978-0-12-811517-6.00008-8

11. K.C. Carpenter, W.L. Breslin, T. Davidson, A. Adams, B.K. McFarlin, British journal of nutrition, 109 (3), pp. 478-486 (2012). DOI: 10.1017/S0007114512001407

12. A. Rieder, S. Ballance, U. Böcker, S. Knutsen, Carbohydrate Polymers, 181, pp. 34-42 (2018). DOI: 10.1016/j. carbpol. 2017.09.044

13. M. Friuoi, L. Gacheu, O. Oprya, M.M. Shamtsyan. Vestnik Mezhdunarodnoi akademii kholoda, 3, pp. 53-61 (2018). DOI: 10.17586/1606-4313-2018-17-3-53-61

14. V. Varelas, M. Liouni, A. C. Calokerinos ,E. T. Nerantzis, Drug Testing and Analysis, 8, pp. 46-55 (2015). DOI: 10.1002/dta.1833

15. Z. Mohebbi, A. Homayouni, M.H. Azizi, S.J. Hosseini, Journal of Food Science and Technology, 55(1), pp. 101-110 (2018). DOI: 10.1007/s13197-017-2836-9 